\title{
Upaya Executive Sous Chef Dalam Mengoptimalkan Penggunaan Bahan Baku Ala Carte Untuk Meningkatkan Kreativitas Commis Di Kitchen Furaya Hotel Pekanbaru
}

\author{
DELFI YANTI \\ Sekolah Tinggi Pariwisata Riau \\ J1. Pattimura No. 54, Cinta Raja, Sail, Cinta Raja, Kec. Sail, Kota Pekanbaru, Riau 28127 \\ E-mail : delviyanti@gmail.com
}

\begin{abstract}
The tourism industry continues to grow to this day where tourism has become an economic locomotive with large foreign exchange contributors. Food And Beverages Department. Food and beverages, especially Food And Beverages Products, which are part of the hotel department that are responsible for providing food and food needs for hotel guests. What is the Effort of the Executive Sous Chef in Optimizing the Use of Raw Materials of A La Carte to Increase Commissiveness in the Furaya Kitchen Hotel Pekanbaru ". This research the author did at Furaya Hotel Pekanbaru. Which will be the population of this study involved all employees in the hotel kitchen along with superiors namely Executive sous chef. 7 Commis, 2 CDP (Chef de party), 2 people For the sake of chef, 1 Executive sous chef and 1 Restaurant cashier. After the data is collected, the data is processed by the discretionary method. The result of the Executive sous chef's response to optimizing the use of raw materials is that the availability of materials that are the main ingredients in the production process is not easy to obtain and the price is very expensive because many use inport materials from Singapore, so optimizing the use of raw materials is a smart solution to anticipate the problem. The sous chef executive has succeeded in increasing Commis' creativity in terms of processing weed scraps as well as food that is still feasible to be consumed as a selling product. There are several obstacles faced by Executive Sous chefs in optimizing the use of raw materials, both from individuals and storage equipment that helps in the production process. Commis creativity improvement has an impact on increasing sales of the a la carte menu, especially the soup menu. This can be seen from the data obtained from the Lotus Caffe chasier, where sales of soup of the day from March to July are increasing
\end{abstract}

Keywords: Sous Chef Executive, Ala Carte Raw Materials, Commis Creativity

Kegiatan pariwisata akan banyak melibatkan komponen dan elemen penting lainnya yang berhubungan erat satu dan lainnya. Industri pariwisata ini terus berkembang sampai saat ini di mana pariwisata telah menjadi lokomotif ekonomi dengan penyumbang devisa yang besar.

Saat ini kita melihat kegairahan untuk pengembangan industri pariwisata semakin menonjol, ini ditandai dengan adanya gairah untuk membangun hotelhotel baru atau hotel yang lama yang melakukan perbaikan yang sangat siknifikan untuk mampu bersaing dalam pelaksanaan kegiatan pengembangan kepariwisataan serta bertujuan untuk meningkatkan perekonomian nasional yang berdampak pada pendapatan devisa Negara yang besar, serta dapat juga berdampak langsung terhadap penyerapan tenaga kerja yang banyak.

Dalam perkembangannya, hotel merupakan salah satu aspek penunjang dalam kegiatan kepariwisataan. Dimana hotel merupakan suatu akomodasi yang dikelola secara komersial untuk menunjang kegiatan kepariwisataan, hal ini menyebabkan hubungan yang sangat erat antara kegiatan wisata dengan hotel. Oleh karena itu hotel menjadi sarana penunjang yang sangat membantu dalam memajukan industri pariwisata saat ini.

Sesuai fungsinya hotel sebagai pemberi jasa akomodasi, hotel harus dikelola secara professional, antara lain menyangkut sistem dan pengorganisasian, prosedur dalam administrasi, dan sistim 
operasional secara keseluruhan. Sehingga akan menciptakan suasana kerja bagi para karyawan yang lebih terarah dan dapat menjalankan SOP (standar operasional prosedur) dengan baik, serta dapat menciptakan profesionalisme dalam menjalankan pekerjaan

Dalam kegiatan operasional sebuah hotel, terdapat beberapa departemen yang saling terkait, antara lain Front Office, Housekeeping, Food And Beverages, Marketing, Engineering, Security, dan lainlain. Namun di kesempatan ini penulis hanya membahas tentang departemen Food And Beverages. Food and beverages khususnya Food And Beverages Product yang merupakan bagian departemen hotel yang bertanggung jawab menyediakan kebutuhan makan dan minun bagi para tamu hotel.

Dalam pengelolaan sebuah hotel memerlukan hubungan kerjasama antara departemen satu dan yang lainnya, seperti bagian makanan dan minuman( food and beverages department). Dalam menjalankan fungsi nya departemen ini di bagi menjadi dua yaitu: Food and beverages product yaitu departemen yang bertugas dalam penyediaan makanan dan minuman bagi para tamu hotel. Food And Beverages Service yaitu departemen yang bertanggung jawab dalam memberikan pelayanan,menjual dan mempersiapkan kebutuhan makan dan minum bagi para tamu tamu.

Dalam pengoperasian sebuah hotel di lakukan oleh beberapa departemen yang sesuai dengan fungsinya masing-masing. Jumlah karyawan yang ada dalam sebuah departemen harus sesuai dengan kebutuhan tamunya. Hal ini bertujuan untuk mengoptimalkan pelayanan bagi para tamu yang dapat menciptakan rasa nyaman bagi para tamu saat barada di hotel. Perencanaan makan dan minuman merupakan sebuah seni yang membutuhkan ilmu pengetahuan serta pengalaman yang berkaitan dengan makanan dan cara penyajiannya.

Untuk menyediakan kebutuhan makan bagi para tamu merupakan tugas dan peranan dari departemen $F \& B$ product, departemen ini merupakan tempat segala kegiatan yang berhubungan dengan pengolahan makanan bagi para tamu yang berada di hotel. Dalam menjalankan peranannya sebagai departemen yang bertanggung jawab terhadap penyediaan kebutuhan makan bagi para tamunnya, departemen ini di pimpin oleh Executive Chef yang bertanggung jawab terhadap kelancaran kegiatan operasional di dapur. Adapun tugas dari executife chef adalah sebagai berikut: Mengelola dan mengawasi penggunaan bahan dan peralatan didapur; Menyusun menu; Membuat standar recipe menu beserta food cost; Membuat perkiraan (forecast) yang akan di capai dalam waktu tertentu; Memimpin staff dan para bawahan nya; Membuat purchase order ( Bartomo $\mathrm{PH}$, 2005;7)

Tujuan yang harus dikerjakan Chef akan beragam, tergantung pada bagian atau seksinya masing-masing. Tapi secara umum dapat dikelompokkan dalam kelompok kerja yang bersifat merencanakan, mengorganisasikan, menggerakkan serta mengawasi cara kerja para bawahan nya. Chef merupakan inti manajemen, karena ia merupakan motor penggerak dari sumber-sumber daya dalam organisasi food And Beverage Product disebuah hotel.

Sukses tidaknya suatu organisasi untuk mencapai tujuan merupakan andil besar yang dipengaruhi oleh kemampuan Chef dalam mengorganisir dan mengoptimalkan sumber daya yang ada di sebuah dapur. Untuk mencapai tujuan organisasinya, Chef harus memiliki standar-standar aturan yang lebih dikenal dengan standar operasional prosedur (SOP).

Standar operasional prosedur adalah suatu pedoman tertulis yang dipergunakan untuk mendorong dan menggerakkan suatu kelompok untuk mencapai tujuan organisasi. Standar operasional prosedur juga merupakan tata cara atau tahapan yang dilakukan dan 
harus dilalui untuk menyelesaikan suatu proses kerja terttentu. Dalam pelaksanaan kerja sehari-hari, para karyawan harus melaksanakan kegiatan kerja sesuai dengan standar operasional yang berlaku disebuah hotel. Adapun dampak yang terjadi akibat tidak berjalannya standar operasional prosedur adalah: Tidak adanya konsistensi dalam tingkat kerja pegawai atau tim organisasi atau unit; Tidak adanya peran yang jelas dari tiap-tiap posisi dalam organisasi; Kerancuan dari tugas, wewenang dan tanggungjawab dari pekerja tersebut; Rawan terjadinya kesalahan administrasi dalam unit kerja sebuah organisasi; Memperbesar tingkat kemungkinan terjadinya kegagalan dan complain dari tamu (Agus Sulastiono, 1998:189)

Untuk mendelegasikan serta menjalankan fungsi dari standar operasional prosedur itu, Executive Chef memiliki jajaran staff yang membantu proses pendelegasian standar operasional prosedur. Di antaranya: Executive Chef; Saus Chef; Chef De Party; Commis; Cook; dan Cook Helper.

Seluruh jajaran ini merupakan urutan rantai informasi yang saling berkesinambungan sehingga informasi yang di peroleh dari Executive Chef dapat di kontribusikan dengan baik melalui Executive sous chef dan di teruskan kepada karyawan yang ada di dapur.

Dalam kegiatan produksi, banyak hal yang harus di perhatikan untuk mengoptimalkan sumber daya baik sumber daya manusia maupun penggunaan bahan baku. Peranan Executive chef sangatlah di perlukan dalam hal mengendalikan penggunaan bahan baku agar proses produksi dapat berjalan secara efektif dan efesien.

Kegiatan produksi yang terjadi di dapur harus mendapatkan perhatian serius dari manjemen agar kelebihan produksi (over production) dapat di tekan sampai pada titik yang paling minimal. (Wiasha,2000)
Hal ini penting dilakukan mengingat harga produk makanan yang dihasilkan sangat perishable. Agar tidak terjadi kelebihan produksi secara siknifikan. Jumlah porsi yang disiapkan terlalu berlebih dibanding yang terjual.bahkan dalam penggunaan bahan baku untuk proses kegiatan produksi sering kali tidak memperhatikan komposisi dan takaran yang diperlukan untuk membuat suatu produk Serta kurangnya pengetahuan tentang penggunaan bahan baku, pemanfaatan sisa bahan produksi dan menanggulangi persentase makanan yang terbuang sehingga terjadi pemborosan yang secara materi dapat merugikan perusahaan.untuk itu perlu perhatian dan pengawasan dari Executife Chef dalam memanfaatkan bahan baku dalam proses produksi.

Dalam kegiatan on the job training yang penulis lakukan di Furaya PekanbaruHotel Bintan, Executive sous chef memegang peran yang besar, di mana Executive sous chef bertanggung jawab langsung terhadap seluruh kegiatan operasional yang berlangsung di kitchen khususnya dalam pemanfaatan bahan baku dan operasional menu di kitchen,

Pemanfaatan bahan baku yang tersedia di kitchen, harus melalui proses pengawasan yang intensif dari Executive sous chef. Hal ini dikarenakan penyediaan bahan bahu produksi yang ada di hotel Furaya Pekanbaru terbatas dan relatif sulit untuk didapatkan. Hal ini dikarenakan lokasi dari hotel Furaya Pekanbaruyang jauh dari pusat kota dan pemukiman warga, sehingga supplier yang melakukan pengadaan bahan baku dilakukan dalam dua kali seminggu. Sehingga untuk menjaga ketersediaan stock bahan perlu diadakan pengawasan terhadap pemanfaatan bahan agar bahan yang ada tidak terbuang sia-sia

Berdasarkan latar belakang di atas maka penulis tertarik untuk membuat suatu penelitian yang bersifat ilmiah yang diberi judul "Upaya Executive Sous Chef Dalam Mengoptimalkan Penggunaan 
Bahan Baku A La Carte Untuk Meningkatkan Kreativitas Commis Di Kitchen Furaya Hotel Pekanbaru"

Dari uraian latar belakang permasalahan yang ada maka perumusan masalah yang penulis kemukakan dalam penelitian ini adalah: " Bagaimanakah Upaya Executive Sous Chef Dalam Mengoptimalkan Penggunaan Bahan Baku A La Carte Untuk Meningkatkan Kretifitas Commis Di Kitchen Furaya Hotel Pekanbaru"

Menurut Webster's kitchen is room or other space as a wall area or separate building with facilities as for cooling artinya: dapur merupakan ruangan atau tempat khusus atau bangunan tersendiri yang mempunyai peralatan untuk memasak makanan yang akan di jual kepada tamu. Di dapur inilah terjadi proses pembuatan masakan

Berdasarkan fungsinya jenis-jenis dapur hotel dibagi menjadi 5 macam diantaranya (Richard Sihite, 2000 : 6) sebagai berikut: Main kitchen (kitchen preparation); Small kichen (pantry kitchen); Settled kitchen (kitchen service); Coffee shop kitchen; Employee feeding/kitchen

Menurut Susno Kardigantara (1998:25) operasional kerja di dalam sebuah kitchen atau dapur hotel menunjukkan halhal sebagai berikut: Proses pengolahan bahan makanan yang siap jual; Memproduksi makanan dengan mutu yang baik; Dengan menjaga area kerja; Memperkecil biaya yang di keluarkan; Pelayanan pemesanan makanan tamu.

Menurut (Bartomo PH, 2005;7) adapun peran Executive sous chef dalah sebagai berikut: Pengatur strategi dalam produksi; Pemasar; Trainer, Pemapar strategi bisnis bagi tiap hotel. Jadi Executive chef dengan multi peran, menunjukkan perubahan yang terjadi di lingkungan masyarakat, yaitu perubahan ekonomi. Politik. Dan tata nilai yang ada.

Tugas Executive chef menurut Richard Sihite (2000 : 27) adalah sebagai berikut: Merencanakan dan menyusun menu; Memesan/mengawasi pemesanan barang serta bahan makanan pada gudang; Merencanakan tata letak (lay out) dapur, baik ruang maupun letak peralatan; Memberikan saran-saran atau data tentang peralatan dapur yang akan dibeli; Menjaga kestabilan food cost (biaya pokok pengolahan makanan), sehingga tingkat keuntungan tertentu dapat dicapai dipertahankan; Mengatur pekerjaan, menentukan uraian tugas-tugas masingmasing jabatan dan menyusun jadwal kerja brigade dapur; Meningkatkan kemampuan bawahan dengan jalan memberikan latihan (training) baik didalam maupun diluar perusahaan; Mengawasi pekerjaan dapur terutama pada waktu service, sehingga kualitas makanan yang dijual dapat dipertanggungjawabkan.

Tugas pokok yang dimiliki seorang Executive sous chef adalah menjadi pendelegasi perintah dari Executive chef. Menurut Bartono PH (2005 : 64) adapun tugas seorang Sous chef antara lain: Menggantikan tugas-tugas Executive chef. Mengawasi pekerjaan chef de partie dan bagian-bagiannya. Mengawasi pengambilan barang di store. Mengawasi pelaksanaan sanitasi dan preparasi. engawasi persiapan lunch, dinner atau banquet secara teknis. Menerima pendelegasian wewenang dari atasan atas hal-hal penting.

Sebagai seseorang yang menjadi tangan kanan Executive chef, dalam kegiatan sehari-harinya banyak di hadapi masalah dari yang berat sampai dengan masalah yang ringan. Untuk itu Evecutive sous chef harus mampu mengelola seluruh potensi yang ada di kitchen agar kegiatan operasional dapat berjalan dengan baik. Menurut Bartono PH dkk (2005 : 10) ruang lingkup pengelolaan meliputi beberapa masalah seperti: Pengelolaan sumber daya manusia; Pengelolaan peralatan produksi; Pengelolaan material bahan olahan; Pengelolaan proses produksi; Pengelolaan biaya produksi; Pengelolaan berbagai sistem yang berlaku diunit produksi; Pengelolaan lingkungan wilayah produksi

Dapur adalah penghasil limbah berupa sampah dan air kotor yang dianggap 
membahayakan lingkungan hidup sekitarnya. Dengan demikian, limbah dapur dan sampah harus dikelola secara baik, bersama limbahlimbah lainnya dari hotel, seperti limbah laundry, limbah dari kamar, dan limbah dari mesin.

Pengolahan makanan yang dilakukan di kitchen, ada beberapa hal yang harus diperhatikan oleh seorang Executive Chef. Adapun hal yang harus diperhatikan adalah sebagai berikut: Manusia, yaitu commis yang memiliki keterampilan, terdidik, dan terlatih dalam mengolah bahan makanan sehingga siap dikonsumsi. Alat-alat yang digunakan harus memenuhi syarat, baik peralatan kecil maupun peralatan besar. Hygiene dan sanitasi, meliputi commis, alat-alat commis, lingkungan tempat pengolahan bahan makanan dan penyajian bahan makanan itu (Ari Fadiati, 1994 : 34)

Menurut (Anwar Prabu, 2005:67) salah satu faktor yang mempengaruhi kompetisi adalah keterampilan kerja, keterampilan kerja seseorang di pengaruhi oleh kemampuan fisik dan kesehatan jiwa individu yang bersangkutan, seperti: pendidikan, akumulasi pelatihan dan pengalaman kerja. Pendidikan dan pelatihan merupakan bagian dari investasi dalam sumber daya manusia, semakain banyak waktu yang di lakukan manusia untuk melakukan pelatihan dan pendidikan semakin tinggi kemampuan dan kompetensi melakukan pekerjaan maka semakin tinggi dan baik kinerjanya.

Menurut Miles, tugas seorang leader adalah ".. that ofimtegrating organizational and human variables into an effective and efficient sociotechnical system ... that of fitting person with an appropriate set of characteristics to them "(Raymon Miles E, 1975:20)

Jadi dalam pengertian tersebut, pimpinan harus mampu membuat orang yang ada diorganisasi memiliki cirri-ciri sesuai dengan goods dan technology. Orang yang berasal dari latar belakang, dengan berbagai karakteristik yang berbeda antara satu dan yang lainnya, harus dapat disatukan dengan tujuan dan pemahaman organisasi. Pimpinan harus mampu mengatasi hal tersebut untuk dapat mencapai tujuan organisasi.

Jadi dalam pembahasan tersebut peran pimpinan sangatlah penting untuk mnyatukan segala latar belakang dan kepribadian tiap anggota karyawannya untuk mencapai tujuan organisasi.

Untuk mencapai aspek-aspek yang akan dicapai seorang pimpinan di dapur, haruslah memperhatikan komponen pendukung yang haarus diperhatikan dalam menjalankan kegiatan operasional. Menurut (Wiber C.Rich 1990:389-390) menyatakan bahwa Executive sous chef harus memenuhi norma-nirma mengenai praktek dan presentasi yang efektif, penilaian haruslah memperhatikan hal-hal berikut: keterkaitan pekerjaan (be job related) dan spesifikasi pekerjaan (job specific), pengukuran tugas yang dilakukan tersebut sesuai dengan pekerjaan yang diuji. Mengukur hanyalah perilaku yang dilihat sesuai dengan stendarstandar mengenai kejelasan dalam susunan kata-kata (wording) yang dapat diterima. Hindarkan pilihan-pilihan perorangan dan subyektifitas (kata-kata seperti ketulusan dan komitmen tidak harus dipakai kecuali secara karakteristik-karakteristik itu bisa diukur). Dicoba hanya sebuah usaha yang disetujui bersama untuk mrmastikan standar-standar performasi kepada para pekerja. Dicoba setelah penilaian selesai dilakukan. Direncanakan pada selang waktu yang menyenangkan. Didokumentasikan dan didukung oleh bukti yang nyata. Dinilai dan diperbarui secara teratur. Tingkat partisipasi dalam bekerja

Makanan yang diperoleh dapur, mengguanakan bahan olahan yang mentah, setengah jadi, ataupun bahan yang sudah jadi. Semua bahan ini harus dikelola secara baik setelah melalui proses pembelian, penerimaan, penyimpanan, pengeluaran dan proses lanjutnya di dapur. Sebagai material berasal dari agro bisnis, peternakan, dan perikanan, industri rumah tangga dan bahan-bahan impor. Pengguanaan hasil industri rumah tangga, agrobisnis dan lainnya, telah membantu perekonomian rakyat, yaitu penghasil produk hasil olahan 
tersebut. Karena keterlibatannya dalam industri perhotelan.(Bartomo PH,2005:87)

Menurut

(Mulyamah,1987;3)

optimalisasi merupakan salah satu ukuran dalam membandingkan rencana penggunaan masukan dengan penggunaan yang di realisasikan atau dengan kata lain penggunaan yang sebenarnya.

Sedangkan pengertian dari optimal menurut(Melayu hasibuan, 1984;233) adalah perbandingan yang terbaik antara input(masukan dan output ( hasil antara keuntungan dengan sumber-sumber yang di gunakan) seperti halnya juga hasil optimal yang dicapai dengan penggunaan sumber yang terbatas

Upaya mengoptimalkan penggunaan bahan baku dimulai dari pada saat barang diambil dari store. Menurut (Bartomo PH,2005:151) semua material yang diambil oleh bagian kitchen dari store harus dipertanggungjawabkan secara akutansi sehingga oleh karenanya harus menunjukan akuntabilitas. Dengan demikian seluruh bahan yang masuk ke kitchen harus dipergunakan secara efesien.

Kreativitas nerupakan potensi yang dimiliki setiap manusia dan bukan merupakan sesuatu yang diterima dari luar individu. Kreativitas yang dimiloki manusia, lahir bersama lahirnya manusia tersebut. Sejak lahir setiap individu sudah memperlihatkan kecendrungan mengaktualisasikan dirinya. Dalam kegiatan yang dilakukan sehari-hari, kreativitas sangatlah diperlukan, karena kreativitas merupakan sesuatu yang sangat penting dalam kehidupan manusia. Harus diakui bahwa sulit untuk menentukan definisi yang operasional dari kreatifitas, karena kreatifitas merupakan konsep yang majemuk dan multidimensional sehingga banyak para ahli yang mengemukakan definisi dari kreatifitas. Menurut Conny R Semiawan(2009: 44) kreatifitas adalah memodifikasi sesuatu yang sudah ada dan menjadi konsep baru. Dengan kata lain, terdapat dua konsep lama yang dikombinasikan menjadi satu konsep yang baru.

Jurnal Daya Saing (Vol. 5, No. 2 Juni 2019)
Menurut Utami Munandar (2009: 12) mengemukakan bahwa kreativitas adalah hasil interaksi antara individu dengan lingkungannya, kemampuan untuk membuat kombinasi baru, berdasarkan datas, informasi atau unsur-unsur yang sudah ada dan dikenal seblumnya, yaitu semua pengalaman dan pengetahuan yang telah diperoleh seseorang selama hidupnya, baik di lingkungan sekolah, keluarga maupun lingkungan masyarakat.

Adapun beberapa cara yang dapat di lakukan untuk memacu kreativitas menurut Nursiti (1999: 34)

1. Aktif membaca

2. Gemar melakukan telaah

3. Giat bereksperimen

4. Mencintai nilai seni

5. Mampu mengikuti perkembangan.

Dalam perkembangan dunia kuliner saat ini seorang Commis harus dituntut untuk brfikir kreatif sehingga Commis mampu menghadapi tantangan global dalam hal penguasaan kemampuan dalam pengolahan berbagai aneka makanan.

Kreativitas dalam diri seorang Commis dapat dilihat oleh seorang Executive sous chef, hal ini dikarenakan secara umum kreativitas mempunya beberapa ciri. Menurut Conni R Semiawan (2009:136) ciri-ciri kreativitas adalah: Berani mengambil resiko. Menguasi dan terampin dalam suatu profesi. Memainkan peran yang positif dan berfikir kreatif. Mampu merumuskan dan mendefinisikan suatu masalah. Tumbuh kembang mengatasi masalah. Toleransi terhadap masalah ganda. Menghargai sesama dan lingkungan sekitar.

\section{METODE}

Penelitian ini penulis lakukan di Hotel Furaya Pekanbaru. Yang akan menjadi populasi penelitian ini melibatkan seluruh karyawan di dapur hotel beserta atasan yaitu Executive sous chef. Yang menjadi sampel dalam penelit yang penulis lakukan adalah ceiteria sebagai berikut: 7 orang Commis; 2 orang CDP (Chef de 
party); 2 orang Demi chef; 1 orang Executive sous chef; 1 orang kasir Restoran.

Teknik pengumpulan data dengan wawancara, Observasi, Persitipan, Angket .Setelah data terkumpul maka data diolah dengan metode diskriktif.

\section{HASIL}

Executive sous chef berperan dalam pendelegasian perintah ataupun tugas yang diberikan oleh Executive chef. Dalam kegiatan operasional yang berlangsung di dapur hotel Furaya Pekanbaru, Executive sous chef melakukan pengawasan terhadap seluruh kegiatan operasional yang terjadi di dapur, hal ini dilakukan agar seluruh kegiatan dapat berjalan sesuai dengan yang diinginkan.

Upaya yang dilakukan Executive sous chef dalam mendelegasikan segala instruksi didalam penggunaan bahan serta pengoptimalan penggunaan bahan di lakukan dengan cara-cara persuasif, seperti memberikan pengarahan pada saat aftenoon briefing yang dilakukan pada saat prgantian shift

Selain itu upaya pengoptimalan bahan baku Executive sous chef selalu melakukan pengawasan terhadap penggunaan bahan baku maupun pemanfaatan bahan sisa produksi yang masi dapat dimanfaatkan, memanfaatkan sisa dalam proses penyiangan serta memanfaatkan bahan yang yang mendekati spoil untuk dapat dimanfaatkan agar tidak menjadi bahan yang terbuang. Adapun upaya yang dilakukan Executive sous chef dalam mengoptimalkan penggunaan bahan baku adalah sebagai berikut

\section{Memberikan pengarahan}

Dalam kegiatan operasional yang berlangsung di kitchen hotel Furaya Pekanbaru kegiatan oper handle sangatlah haus dilakukan antar shift, hal ini bertujuan untuk melancarkan kegiatan operasional yang akan dilakukan oleh shift berikutnya.

Kegiatan oper handle atau serah terima biasanya dilakukan pada saat briefing yang dilakukan jam 2 siang. Selain bertujuan untuk melakukan kegiatan oper handle, briefing juga dimanfaatkan oleh sous chef untuk mengefaluasi kinerja para staff pada hari tersebut selain itu banyak hal-hal yang dibicarakan baik yang berhubungan dengan pekerjaan shift berikutnya maupun hal yang berhubungan dengan persiapan event serta break fast keesokan hari.

Moment briefing ini juga dimanfaatkan sous chef untuk selalu memberikan masukan maupun perintah yang berkaitan dengan pemanfaatan bahan sisa penyiangan maupun makanan sisa breakfast yang masi bisa di manfaatkan untuk keesokan harinya.

Kegiatan rutin yang dilakukan sous chef dalam hal pendelegaisian maupun pemberian wawasan baru terhadap penggunaan bahan yang ada di kitchen selain melalui proses briefing yang di lakukan setiap pergantian shif, juga dilakukan tiga bulan sekali melalui proses efaluasi kinerja staff. Kegiatan ini rutin di lakukan selain bermanfaat untuk memberikan masukan dan pengarahan terhadap kinerja para staff nya, hal ini juga bermanfaat untuk memberikan kesempatan para staff untuk berbicara empat mata kepada sous chef mengenai kelancaran kegiatan operasional termasuk strategistrategi yang dapat di lakukan untuk peningkatan efesiensi penggunaan bahan baku.

\section{Memanfaatkan bahan sisa produksi yang berasal dari bahan sisa penyiangan yang masi layak digunaka}

Pemanfaatan bahan baku yang dilakukan dari proses penyiangan merupakan salah satun upaya yang dilakukan Sous chef dalam menghemat penggunaan bahan baku serta meminimalisir bahan-bahan yang masih memiliki nilai guna agar tidak terbuang siasia. Hal ini dilakukan selain untuk melakukan penghematan dan dapat memberikan tantangan baru bagi para Commis untuk memanfaatkan bahan yang seharusnya dibuang namun dapat diolah menjadi sesuatu yang memiliki nilai jual. 
Selain itu mengingat lokasi dari hotel Furaya yang terletak di pusat kota,yang menyebabkan pengadaan bahan baku yang diperlukan dalam proses produksi cukup sulit intuk mendapatkannya, dimana suppiyer tidak setiap hari mengantarkan bahan baku yang diperlukanhotel Furaya Pekanbaru. Dari permasalahan tersebut, Executive sous chef harus dapat menggunakan dengan baik bahan agar tidak terjadi kekosongan stock bahan yang dapat berdampak secara langsung terhadap proses produksi. Executive sous chef harus bisa mensiasati penggunaan bahan baku. Untuk itu executive sous chef sering memberikan informasi-informasi tentang cara maupun gambaran nyata kepada staff dalam pengolahan bahan tersebut. bahanbahan yang dapat dimanfaatkan dari proses penyiangan diklasifikasikan ke dalam dederapa jenis

\section{Mengolah ulang bahan makanan yang sudah melalui proses masak yang masi layak dimanfaatkan}

Pemanfaatan bahan makanan yang dapat diolah dan dijadokan siatu produk olahan baru bukan hanya berasal dari bahanbahan sisa proses trimingan. Namun juga berasal dari bahan makanan yang sudah melalui proses olahan, tetapi tidak habis.

Adapun upaya nyata dalam pemanfaatan bahan sisa makanan ini seperti sisa makanan breakfast yang masi layak untuk digunakan saat breakfast keesokan harinya, makanan yang berasal dari buffet lunch, dinner serta event yang rutin diadakan seperti Indonesian BBQ yang diadakan hari sabtu malam.

Kegiatan pengoptimalan bahan baku yang dilakukan Executive sous chef ini perlu dilakukan pengawasan terhadap penempatan. Penyimpanan serta pengolahan. Bahan baku yang sudah melalui proses masak memang tidak bertahan lama. Untuk itu pada saat penyimpanan dilakukan proses penanggalan (labeling) untuk mengetahui batas layak nya penggunaan bahan baku tersebut. Waktu yang di tetapkan oleh Executive sous chef untuk penyimpanan bahan yang sudah melalui proses pemasakan ini hanya lah 3 hari, untuk itu Executive sous chef selalu memberitaukan kepada para Commis untuk mengolah bahan tersebut sebelum bahan tersebut dinyatakan rusak, hampir semiua jenis makanan siisa buffet dapat diolah dan dimanfaatkan menjadi prodak baru yang layak dan memiliki nilai jual. Dari keseluruhan kegiatan tersebut apabila bahan sisa dari buffet tidah memungkinkan untuk disimpan dan diolah kembali, maka prodak olahan tersebut ditransfer ke kantin untuk makan karyawan.

\section{PEMBAHASAN}

\section{Pengaruh dari pngoptimalan penggunaan bahan baku terhadap kreativitas Commis di dapur hotel Furaya Pekanbaru}

Pengooptimalan penggunaan bahan baku yang dilakukan oleh Executive sous chef selain dapat meminimalisir bahan baku yang terbuang sia-sia yang dapat mengurangi nilai guna dari suatu bahan baku, upaya ini jiga berdampak dengan meninggkatnya kreatifitas Comnis dalam memanfaatkan sisa produksi maupun makanan sisa yang masi layak digunakan, sehingga dapat meminimalisir bahan yang masi memiliki nilai jual terbuang sisa-sia. Dalam mewujudkan tujuan tersebut, seorang Executive sous chef selalu memberikan masukan maupun treining terhadap para Commis agar wawasan mereka bertambah dalam hal pengolahan bahan. Upaya yang dilakukan Executive sous chef ternyata tidak sia-sia. Terlihat dari pengetahuan Commis yang dapat mengolah bahan-bahan yang seharusnya menjadi sampah, namun dapat diolah menjadi bahan tambahan, bahan dasar maupun menu yang sangt lezat yang dapat memikat para tamu untuk mencicipinya.

Untuk itu, commis selalu mendapatkan perhatian dan pengawasan dari Executive sous chef dalam kegiatan produksi sehari-hari. Hal ini dilakukan agar Commis dapat membuka wawasan dalam upaya penolahan bahan sisa menjadi menu baru ataupun memanfaatkan bahan sisa 
menjadi bahan dasar olahan suatu prodak. Tidak hamya mengawasi, Executive sous chef sering memberikan arahan tentang jenis. Karakter ,ataupun citarasa yang dapat dihasilkan dari bahan sisa produksi tersebut. Sehingga Commis dapat melakukan inovasi baru dalam kegiatan produksi sehari-hari serta dapat memanfaatkan bahan sisa dengan efektif dan efesien.

Tolak ukur yang diperhatikan penulis dalam melihat berhasil atau tidaknya upaya yang dilakukan Executive souce chef dalam meningkatkan kreatifitas Commis trlihat dari aneka ragam soup yang dihasilkan dari kreatifitas Commis dalam memanfaatkan bahan baku yang bersifat trimingan maupun sisa makana yang masi layak untuk diolah. Dalam aplikasi nya soup yang dihasilkan dari bahan sisa maupun makanan sisa dikatagorikan dalam menu soip of the day (SOD).

Aneka ragam soup yang dihasilkan dari bahan sisa dapat memacu Commis untuk berfikir kreatif sehingga terciptalah aneka soup yang dapat dijadikan salah satu menu pembuka bagi para tamu.

Selain bahan sisa yang digunakan untuk bahan dasar pembuatan soup, bahan-bahan sisa juga di gunakan untuk bahan tambahan dalam pembuatan aneka paste seperti: Tomato paste; Sambal belacan paste; Bologneise paste; Sambal rica-rica paste; Sambal jimbaran paste; Tandori paste; Stock (white and brown) dan sebagainya.

Masih banyak lagi bahan sisa trimingan mupun bahan makanan sisa yang masi bisa digunakan untuk diolah menJadi makanan yang memiliki nilai jual maupun bahan tambahan unruk menghasilkan suatu prodak yang masi bisa digunakan, sehingga tidak ada lagi bahan baku maupun makanan yang terbuang .

Antisipasi terahir ataupun langkah terahir yang dilakukan untuk makanan sisa yang ada di kitchen agar tidak terbuang siasia adalah dengan meletakkannya Employe Dinning Room (EDR). Walaupun kitchen Lotus tidak bertugas untuk pengadaan makan karyawan yang sudah menjadi tanggung jawab staff kantin Banyan Tree, namun prosedur yang berlaku di hotel Furaya Pekanbaruapabila makanan sisa breakfast, lunch maupun dinner yang berlebih dan masi layak serta baik untuk dimakan, maka makanan tersebut diletakkan ke EDR dan menjadi makanan tambahan karyawan

\section{Pengaruh pengoptimalan penggunaan bahan baku terhadap penjualan menu $a$ la carte khususnya menu soup}

Pengoptimalan penggunaan bahan baku yang dilakukan Executive sous chef berdampak terhadap peningkatan nilai guna dari suatu bahan tersebut dan juga berdampak terhadap peningkatan kreativitas dari para Commis di kitchenhotel Furaya Pekanbaru. Selain itu peningkatan kreativitas dari Commis memberikan keuntungan yang cukup siknifikan terhadap penjualan menu a la carte khususnya menu soup di lotus caffe

Kemampuan Commis yang dapat memanfaatkan bahan sisa olahan menjadi produk yang bermanfaat dan dapat mendatangkan keuntungan bagi hotel. Dengan kata lain Executive sous chef barhasil meningkatkan kreativitas Commis dalam hal mengolah bahan sisa, sehingga biaya yang digunakan untuk membuat suatu menu SOD relatif kecil dan memperoleh hasil yang besar.

Dari kegiatan on the job treining yang saya lakukan, saya memdapatkan data penjualan soup yang meningkat dari setiap bulannya, berikut adalah tabel penjualan soup of the day yang berhasil saya peroleh dari casier lotus caffe selama bulan maret sampai dengan bulan juli. Harga perporsi dari menu soup of the day adalah USD 8,00. Pada bualan Maret hasil penjualan sebesar USD 896, bulan April USD 936, bulan Mei USD 1,072, bulan Juni USD 1,128 dan pada bulan Juli sebesar USD 1,152 .

Dari data di atas dapat saya simpulkan bahwa setiap bulannya penjualan SOD selalu bertambah dilihat dari hasil data yang diperoleh selama 5 bulan, dampak dari peningkatan kreatifitas Commis dalam hal penolahan bahan sisa 
penyiangan maupun bahan sisa makanan yang masi layak diolah dapat berdampak pada penjualan menu a la carte khususnya menu soup yang ada di Lotus Caffehotel Furaya Pekanbaru.

\section{Kendala yang dihadapi oleh Executive sous chef dalam mengoptimalkan penggunaan bahan baku untuk meningkatkan kteativitas Commis}

Upaya Ececutive sous chef dalam mengoptimalkan penggunaan bahan baku bertujuan untuk meminimalisir terbuangnya bahan yang masi memiliki nilai guna dan nilai jual selain itu dapat menjaga ktersediaan stock bahan baku . prioritas utama yang diharapkan dari pengoptimalan penggunaan bahan baku adalah untuk memacu Commis berfikir kreatif dalam mengolah bahan sisa menjadi bahan yang berharga dan nilai dari bahan tersebut meningkat.

Untuk mewujutkan itu semua Executive sous chef melakukan berbagai cara dan upaya agar wawasan Commis terhadap pengolahan bahan baku menjadi bertambah sehingga Commis dapat memacu fikirannya untuk merfikir kreatif dalam pengolahan bahan sisa menjadi bahan yang bermanfaat.

Namun dalam pelaksanaan program nya, Executive sous chef mendapatkan kendala yang berpengaruh terhadap upayanya untuk pengoptimalan bahan baku tersebut. Dalam kegiatan on the job training yang saya lakukan dihotel Furaya Pekanbaru, saya berkesempatan untuk melakukan sesi wawncara dengan Chef Yudhistira Angga Titya yang merupakan Executive sous chef Hotel serta orang yang memberikan pengetahuan serta pengawasan kepada kami para treining dan para staff kitchen tentang pengoptimalan penggunaan bahan baku.

Adapun beberapa kendala yang di hadapi diantaranya:

a. Karakter individu yang tidak mudah untuk dirubah. Dalam sesi wawancara yang saya lakukan di office Chef Angga pada tanggal 3 juli 2014 beliau menceritakan tentang kendala yang dihadapi dalam upaya pengoptimalan penggunaan baha baku, diantaranya karakter individu yang tidak mudah untuk diubah. Beliau menyadari setiap staff nya memiliki karakter dan wawasan tentang operasional dapur yang berbeda. Selain faktor lingkungan dan kebiasaan, faktor pendidikan juga berpengaruh terhadap karakter dan wawasan setiap individu. Berikut daftar nama staff kitchen lotus beserta jabatan dan pendidikan terahirnya Dapat kita lihat bahwa pendidikan yang dimiliki oleh para staff berbeda, sehingga wawasan dan pengetahuan tentang kegiatan operasional dan bahan baku juga tidak sama antara satu dan lainnya.

b. Kurangnya pengawasan. Rasa peduli yang tidak setabil merupakan sikap yang harus mendapat perhatian oleh Chef Angga. Dirasakan olehnya beberapa staff harus selalu mendapat pengawasan dikarenakan kepedulian yang berubah-ubah sehingga terkadang sangat peduli terhadap bahan baku sisa tetapi diluar pengawasan terkadang rasa acuh itu pun muncul sehingga pengawasan yang extra harus dilakukan agar tercapainya tujuan penggoptimalan penggunaan bahan tersebut

c. Bahan baku yang datang sudah dalam keadaan yang kurang baik. Pengorderan bahan baku yang dilakukan oleh lotus kitchen ke bagiant butcher terkadang bahan yang datang sudah dalam keadaan yang kurang baik. Staff kitchen yang membuat orderan tidak dapat menyalahkan $100 \%$ pihak butcher dikarenakan stock barang yang datang ke chiller bucher dilakukan dalam keadaan banyak dalam durasi satu minggu hanya dua kali pengorderan barang ke pihak supplier, sehingga Chef Angga harus pintar mensiasati penggunaan bahan yang kurang baik ini

d. Fasilitas penyimpanan yang sudah 
tua. Peralatan penyimpanan yang sudah tua juga merupakan kendala yang dihadapi Chef Angga. Usia penyimpanan bahan baku yang sudah lebih dari 15 tahun sering kali mengalami gangguan dalam hal suhu yang tidak setabi. Sehingga bahan yang ada didalam chiller menjadi rusak.

\section{SIMPULAN}

Berdasarkan hasil dari tanggapan Executive sous chef tentang pengoptimalan penggunaan bahan baku sangatlah perlu dilakukan mengingat ketersediaan bahan yang menjadi bahan utama dalam proses produksi tidak mudah didapat dan harganya sangat mahak dikarenakan banyak menggunakan bahan inport dari singapura, sehingga pengoptimalan penggunaan bahan baku merupakan solusi yang cerdas untuk mensiasati masalah tersebut.

Executive sous chef berhasil meningkatkan kreativitas Commis dalam hal pengolahan bahan sisa penyiangan maupun sisa makanan yang masi layak untuk dikonsumsi menjadi prodak yamg memiliki nilai jual. Ada beberapa hambatan yang dihadapi Executive sous chef dalam pengoptimalan penggunaan bahan baku, baik itu berasal dari individu maupun peralatan penyimpanan yang membantu dalam proses produksi

Peningkatan kreativitas Commis berdampak kepada peningkatan penjualan menu a la carte khususnya menu soup. Hal ini terlihat dari data yang diperoleh dari chasier Lotus Caffe, dimana penjualan soup of the day dari bulan maret sampai dengan bualan juli mengalami peningkatan.

\section{DAFTAR RUJUKAN}

Amir, M. Taufiq. 2005. Dinamika Pemasaran Jelajahi dan Rasakan. PT. Raja Grafindo Persada. Jakarta

Arief Hussien, 2006. Buku Petunjuk Penyusunan Proposal dan Makalah.
Akademi Pariwisata Engku

Puteri Hamidah. Pekanbaru.

Siswanto Sastrohadiwiryo. 2005. Manajemen Tenaga Kerja Indonesia. Bumi Aksara. Jakarta.

Cadoso, Fautino Gomes. 2003. Manajement sumber daya manusia, Andi. Yogyakarta.

Fandy Tjiptono. 2005. Pemasaran Jasa. Bayumedia Publishing. Malang

Giese, J. L. and J. A. Cote. 2000. Defining Customer Satisfaction. Binapura Aksara. Jakarta

Hasibuan Melayu. 2003. Manajemen Sumberdaya Manusia. Andi. Yogyakarta.

http://kelompok9tibg.blogspot.com/2012/07 /peranan-teknologi-informasipada- usaha_09.html.

http://dahliasueno.blogspot.com/2011/09/pe ranan-cook-di-kitchen.html.

http://azizrahma.blogspot.com/2013/02/23/konsep-kreatifitas-pengukurankreatifitas html.

IBM Wiyasha. 2003. Manajemen untuk Hotel dan Restoran. Andi. Jakarta.

Kardigantara Suseno. 1998. Perencanaan Dapur Satu ( 1 ). Sekolah Tinggi Pariwisata Bandung.

Kotler, Philip. 2000. Manajemen Pemasaran. Edisi Milenium. Prehallindo. Jakarta.

Lupiyoadi, Rambat. 2001. Manajemen Pemasaran Jasa. PT. Salemba Empat. Jakarta. 
MA Hutomo. 2005. Kamus Lengkap Bahasa Indonesia. Penerbit Mitra Pelajar. Surabaya.

Mangunhardjana,

A.M.

Mengembangkan

Kansius, Yogyakarta.

Marsum WA. 1995. Restoran Dan Segala Permasalahannya. Andi Offset. Yogyakarta.

McKenna, R. 1991. Relationship Marketing: Successful Strategies for the Age of the Customer. Gramedia. Jakarta.

Moehyi, S. 1999. Penyelenggara Makanan Institusi Dan Jasa Boga. Penerbit Pt Bharata. Jakarta.

Munandar, S. C. Utami. 1999. Kreativitas Dan Keberbakatan: Strategi Mewujudkan Potensi kreatif dan bakat. Gramedia. Jakarta.

Nasution, M. N. 2005. Manajemen Mutu Terpadu (Total Quality Management). Ghalia Indonesia. Bogor.

Peter dan Olson. 1996. Perilaku Konsumen dan Strategi Pemasaran. Gelora Aksara Pratama. Jakarta

P.H. Bartono dan E. M, Ruffino. 2006. Food Product Management Di Hotel Dan Restoran. Andi. Yograkarta. . 2001. Pengantar Pengolahan Makanan. Perca. Jakarta.

Sihite, Richard. 2000. Hotel Management. SIC. Surabaya.

Soenaryo Adi. 2001. Kamu Istilah Pariwisata Dan Perhotelan. Penerbit Angkasa. Bandung.

Sumarwan, Ujang. 2003. Perilaku Konsumen. Penerbit Ghalia Indonesia. Jakarta.
Suryabrata Sumadi. 2003. Metodologi Penelitian. PT. Raja Grafindo Persada. Jakarta.

Tim Penyusun Materi. Buku Petunjuk Penyusunan proposal Dan Makalah. Akademi Pariwisata Engku Puteri Hamidah.

Wilkie, L. 1994. Consumer Behavior. Grafindo Persada. Jakarta. 